Article

\title{
Vitamin C and Phenolic Antioxidants of Jua (Ziziphus joazeiro M.) Pulp: A Rich Underexplored Brazilian Source of Ellagic Acid Recovered by Aqueous Ultrasound-Assisted Extraction
}

\author{
Thaís Silva da Rocha ${ }^{1}$, Alessandro de Lima ${ }^{2} \mathbb{D}$, Jurandy do Nascimento Silva ${ }^{2}$, Geni Rodrigues Sampaio ${ }^{3} \mathbb{D}$, \\ Rosana Aparecida Manólio Soares Freitas ${ }^{3}$, Renan Danielski ${ }^{4}$, Adriano Costa de Camargo ${ }^{5, *(D)}$, \\ Fereidoon Shahidi 4 (D) and Elizabeth Aparecida Ferraz da Silva Torres ${ }^{3, *}$ \\ check for \\ 1 Department of Nutrition, Universidade Federal do Piauí-UFPI, Teresina 64049-550, PI, Brazil; \\ thais.rocha@ifma.edu.br \\ 2 Instituto Federal de Educação, Ciência e Tecnologia do Piauí-IFPI-Zona Sul, Teresina 64000-040, PI, Brazil; \\ alessandro@ifpi.edu.br (A.d.L.); jurandy@ifpi.edu.br (J.d.N.S.) \\ 3 School of Public Health, Universidade de São Paulo-USP, São Paulo 01246-904, SP, Brazil; \\ genirs@usp.br (G.R.S.); rosanaso@usp.br (R.A.M.S.F.) \\ 4 Department of Biochemistry, Memorial University of Newfoundland, St. John's, NL A1C 5ST, Canada; \\ rdanielski@mun.ca (R.D.); fshahidi@mun.ca (F.S.) \\ 5 Nutrition and Food Technology Institute, University of Chile, Santiago 7830490, Chile \\ * Correspondence: adrianoesalq@gmail.com (A.C.d.C.); eatorres@usp.br (E.A.F.d.S.T.)
}

updates

Citation: da Rocha, T.S.; de Lima, A.; Silva, J.d.N.; Sampaio, G.R.; Soares Freitas, R.A.M.; Danielski, R.; de Camargo, A.C.; Shahidi, F.; Torres, E.A.F.d.S. Vitamin C and Phenolic Antioxidants of Jua (Ziziphus joazeiro M.) Pulp: A Rich Underexplored Brazilian Source of Ellagic Acid Recovered by Aqueous Ultrasound-Assisted Extraction.

Molecules 2022, 27, 627.

https://doi.org/10.3390/

molecules27030627

Academic Editor:

Urszula Gawlik-Dziki

Received: 11 November 2021

Accepted: 15 January 2022

Published: 19 January 2022

Publisher's Note: MDPI stays neutral with regard to jurisdictional claims in published maps and institutional affiliations.

Copyright: (C) 2022 by the authors. Licensee MDPI, Basel, Switzerland. This article is an open access article distributed under the terms and conditions of the Creative Commons Attribution (CC BY) license (https:// creativecommons.org/licenses/by/ $4.0 /)$.

\begin{abstract}
Jua (juá in Portuguese) is an underexplored fruit from Brazil's northeast. This fruit is rich in antioxidant substances. However, there is a dearth of information about jua's bioactive potential. The present study evaluated two extraction methods (continuous agitation and ultrasound-assisted extraction-UAE) and employed three different solvents (water, ethanol, and acetone) to efficiently recover soluble phenolic compounds. Aqueous extracts obtained by UAE showed the highest total phenolic content (TPC) and antiradical activity. Besides being an eco-friendly procedure, extraction and/or solubility in an aqueous medium is also important for food application. Ellagic acids were the predominant phenolics (80\%) found in aqueous jua pulp extract obtained by UAE, as determined by HPLC, while its TPC was 405.8 gallic acid equivalent per gram of fruit. This extract also exhibited a higher scavenging activity towards peroxyl radicals when compared to that of several other fruits from the literature, including grape, strawberry, cranberry, and walnuts, which are known references in terms of antioxidants. This is the first report that demonstrates jua pulp's potential as an alternative source of ellagic acid and other phenolic acids and flavonoids. Therefore, the outcome of this study provides new information that can be useful for functional food and nutraceutical industries.
\end{abstract}

Keywords: polyphenols; ellagic acid; gallic acid; ultrasound-assisted extraction; underexplored fruits

\section{Introduction}

The juazeiro tree (Ziziphus joazeiro M.), which belongs to the family Rhamnaceae, grows in the Brazilian northeast and is characterized for thriving under adverse climatic conditions encountered in the caatinga desert, namely hot and dry winter as well as cold and rainy summer. Parts of the tree, such as the leaves, are used in folk medicine to treat respiratory conditions, such as asthma, pneumonia, and bronchitis, as well as other ailments (e.g., headache, fever, skin rash) [1]. The plant bears small round-shaped fruits, known as jua, possessing a yellow color, sweet taste, and a seed in its core (Figure 1). Although used by the local population, scientific data on jua's chemical composition is scarce. Evidence points out that the fruit is highly concentrated in bioactive compounds, including vitamin $\mathrm{C}$ and phenolic compounds [1,2]. 


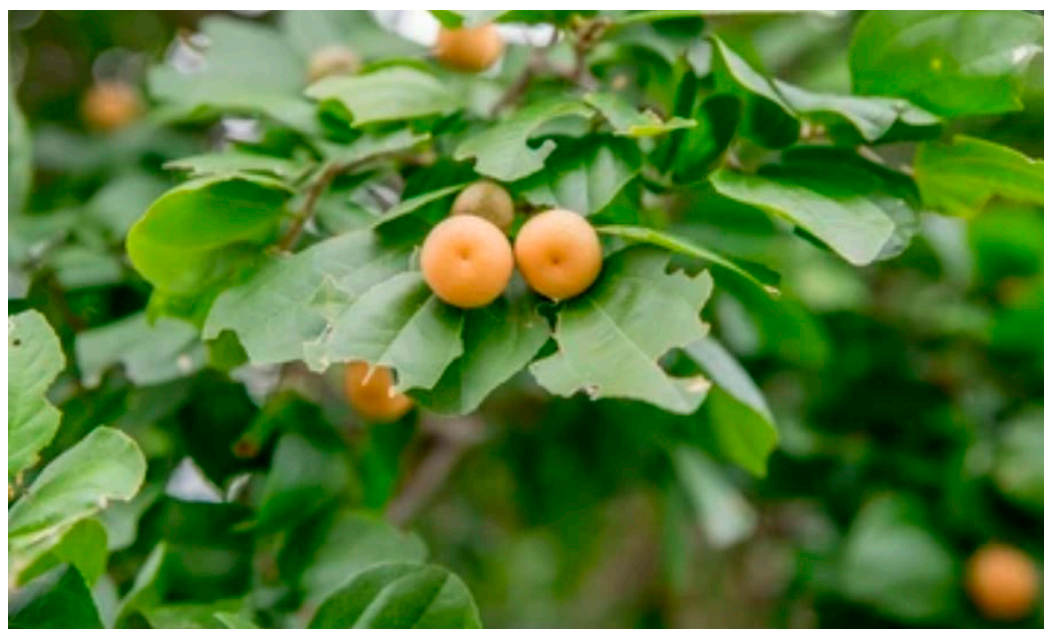

Figure 1. Juá (Ziziphus joazeiro M.) fruit. Source: https:/ /www.shutterstock.com/pt/image-photo/ fruits-de-boi-1076258687 (accessed on 15 January 2022).

Health-promoting benefits have been ascribed to the consumption of fruits and vegetables [3], which, among other factors, could be associated with the presence of phenolic compounds. This large group of plant secondary metabolites is characterized for their ability to scavenge free radicals primarily by the donation of a hydrogen atom or an electron, interrupting the propagation of oxidation [4]. Oxidative stress can occur in the body when there is an accumulation of reactive oxygen species (ROS), and this condition is related to the development of several chronic ailments, such as cardiovascular diseases, some types of cancer, diabetes, obesity, and anti-inflammatory disorders. The consumption of antioxidants, such as phenolic compounds, along with a healthy lifestyle, may help in lowering the risk of developing these diseases $[5,6]$.

In order to fully understand the potential of underexplored antioxidant sources such as jua, it is necessary to extract the relevant bioactive compounds from the fruit and analyze their composition. For instance, soluble phenolics can be obtained by several techniques, each having its own advantages and pitfalls. Among possible approaches, ultrasoundassisted extraction (UAE) stands out for its simplicity, economical apparatus, low solvent use, and the possibility of simultaneously conducting several experiments. Besides, the time required for each extraction is relatively short, ranging from 20 and $40 \mathrm{~min}$ on average [7].

UAE relies on the acoustic cavitation phenomenon, by which the formation and collapse of microbubbles generate specific sites with extreme temperature $(5000 \mathrm{~K})$ and pressure (1000 atm), causing higher shear and turbulence in the cavitation area. This effect helps disrupt the plant tissue, which increases the rate of solvent penetration. Additionally, the ultrasonic waves promote hydration and swelling of the material, increasing the pore size and creating a sponge-like effect, which optimizes the interchange between liquids from inside the pores and the matrix's surface, enhancing mass transfer [8,9]. According to Ma et al. [10], UAE has also attracted commercial interest over the years due to its reduced extraction time, cost-effectiveness, the possibility of scaling-up, and reduced solvent use.

Especially for new or underexplored feedstocks, an appropriate solvent should be chosen to ensure the dissolution and full extraction of the target compounds. For phenolic compounds, water, methanol, ethanol, and acetone are the most common solvents used either alone or in combination [8]. Therefore, the objective of this study was to explore the chemical composition of jua, with an emphasis on its phenolic composition and antiradical activity towards peroxyl radicals. In addition, for the first time, combinations of two extraction methods (continuous agitation and ultrasound-assisted extraction) with three solvents (water, ethanol, and acetone) were employed to investigate the best conditions for the highest extraction efficiency of soluble phenolic compounds. 


\section{Results and Discussion}

\subsection{Vitamin C}

Ascorbic acid (vitamin C), a vitamin antioxidant, was present at $87.28 \mathrm{mg} / 100 \mathrm{~g}$ in jua pulp. This value is higher than those of common fruits such as apple $(5.7 \mathrm{mg} / 100 \mathrm{~g})$, red grape (4.0 mg/100 g), strawberry (37 mg/100 g), lemon (46 mg/100 g), peach $(6.6 \mathrm{mg} / 100 \mathrm{~g})$, orange (45 mg/100 g), banana (9.1 mg/100 g), pear (4.0 mg/100 g), pineapple (15.4 mg/100 g), and grapefruit (37 mg/100 g) [11]. As humans cannot synthesize this compound, it needs to be acquired through the diet. In light of this, jua pulp has been shown to be a rich source of vitamin $\mathrm{C}$, contributing to the fruit's health benefits.

Ascorbic acid is a water-soluble vitamin of utmost biological significance. Besides preventing the common cold, some other roles assumed by ascorbic acid include participation in the metabolism of tyrosine, folic acid, and tryptophan, lowering of cholesterol, contribution to the synthesis of carnitine and catecholamine to regulate the nervous system, tissue growth and wound healing, among others. Besides, as an antioxidant molecule, this vitamin can retard oxidative stress, and it has been related to anticancer and anti-diabetic effects [12].

Due to the antioxidant nature of ascorbic acid, in vitro assays used to estimate the antioxidant activity are also affected by this molecule's presence in case of it being coextracted with other antioxidants, such as phenolics [12]. Therefore, it is important to quantify the amount of vitamin $C$, so the results can faithfully reflect the compounds that contribute to the samples' antioxidant potential.

\subsection{Effect of Extraction Method on Total Soluble Phenolic Content}

In order to evaluate how the solvent system and the extraction method can affect the phenolic content of jua pulp, the extraction was conducted through continuous agitation (CA) and ultrasound-assisted extraction (UAE), using water, ethanol (logP of -0.31 ), or acetone $(\log \mathrm{P}$ of -0.24$)$ as solvents. Results for the extracts' total phenolic contents (TPC) are shown in Table 1.

Table 1. Total soluble phenolic content (mg GAE/100 g FW) of jua (Ziziphus joazeiro M.) obtained by continuous agitation (CA) and ultrasound-assisted extraction (UAE) using different solvents.

\begin{tabular}{ccc}
\hline Solvent & CA & UAE \\
\hline Water & $338.7 \pm 29.00 \mathrm{Ab}$ & $405.8 \pm 6.01 \mathrm{Aa}$ \\
Ethanol & $314.2 \pm 12.45 \mathrm{Ab}$ & $394.9 \pm 24.4 \mathrm{Aa}$ \\
Acetone & $271.5 \pm 1.78 \mathrm{Ba}$ & $275.1 \pm 15.87 \mathrm{Ba}$ \\
\hline
\end{tabular}

GAE, gallic acid equivalent; FW, fresh weight. Results are expressed as mean $(n=3) \pm$ standard deviation (SD) Results followed by the same lowercase letter in the row and the same uppercase letter in the column do not differ significantly (Tukey's test, $p<0.05$ ).

The combination of UAE with water (405.8 mg GAE/100 g) and/or ethanol (394.9 mg GAE/100 g) rendered the highest total phenolic content from all the combinations tested, followed by the extract obtained using acetone and UAE (275.1 mg GAE/100 g). Therefore, UAE proved to be a more efficient extraction technique when compared with continuous agitation, obtaining higher phenolic yields.

The use of ultrasound as an extraction technique can yield compounds not possible to be released by conventional approaches, such as maceration. Lima [13] was able to recover a total of 37 phenolic compounds from guava's pulp and processing by-products by using UAE, including ellagic acid, gallic acid, quercetin, as well as phenolics never reported before for this fruit, such as umbelliferone, carnosol, and syringaldehyde. Mazza [14] also reported a positive outcome when using ultrasound extraction to obtain phenolics from syrah grape skin. Their optimization study revealed that an ultrasonic power of $3000 \mathrm{~W} / \mathrm{L}$, $2.5 \%$ citric acid, and solid:liquid ratio of 1:15 yielded the highest levels of total phenolics, monomeric anthocyanins, and antioxidant capacity measured by ORAC and ABTS assays. 


\subsection{Identification of Phenolic Compounds by High-Performance Liquid Chromatography (HPLC)}

Table 2 shows the phenolic compounds identified in jua pulp extracts by HPLC analysis, with their respective quantities. Overall, the main compounds present in the aqueous extract obtained by UAE (highest total phenolic content) were ellagic acid, followed by gallic acid and epicatechin. Ellagic acid is a potent antioxidant, mainly due to the presence of multiple hydroxyl groups in the ortho position in the molecule, contributing to its ability to donate hydrogen atoms, and stabilizing free radicals. Further studies may be focused on optimizing the conditions (e.g., temperature, extraction time, $\mathrm{pH}$, etc.) to increase the recovery of ellagic acid as the most prominent compound [15].

Table 2. Phenolic compounds in jua pulp extracts obtained upon ultrasound-assisted extraction.

\begin{tabular}{cccc}
\hline \multirow{2}{*}{ Phenolic Compound } & \multicolumn{4}{c}{ Extracts $(\mu \mathrm{g} / \mathrm{g}$ FW) } \\
\cline { 2 - 4 } & \multicolumn{4}{c}{ Ethanol } & Acetone \\
\hline Phenolic acids & \\
\hline Gallic acid & $29.30 \pm 2.8 \mathrm{aA}$ & $32.66 \pm 2.6 \mathrm{aA}$ & $16.50 \pm 1.4 \mathrm{bA}$ \\
\hline$p$-Coumaric acid & $0.64 \pm 0.1 \mathrm{aB}$ & $0.58 \pm 0.1 \mathrm{bB}$ & $0.99 \pm 0.10 \mathrm{aB}$ \\
\hline Sinapic acid & $5.56 \pm 0.2 \mathrm{aB}$ & $3.48 \pm 0.3 \mathrm{bB}$ & $0.82 \pm 0.2 \mathrm{cB}$ \\
\hline Ellagic acid & $210.44 \pm 20.1 \mathrm{aC}$ & $210.97 \pm 17.1 \mathrm{aC}$ & $192.13 \pm 14.3 \mathrm{aC}$ \\
\hline \multicolumn{4}{c}{ Flavan-3-ols } \\
\hline Catechin & $4.51 \pm 1.1 \mathrm{aB}$ & $6.14 \pm 0.3 \mathrm{aB}$ & $12.55 \pm 1.7 \mathrm{bA}$ \\
\hline Epicatechin & $9.23 \pm 0.4 \mathrm{aAB}$ & $7.56 \pm 1.2 \mathrm{abB}$ & $6.30 \pm 0.80 \mathrm{bAB}$ \\
\hline Quercetin & $1.62 \pm 0.1 \mathrm{aB}$ & $1.54 \pm 0.2 \mathrm{aB}$ & $1.27 \pm 0.3 \mathrm{aAB}$ \\
\hline Total $(\mu \mathrm{g} / \mathrm{g}$ FW $)$ & 261.30 & 262.93 & 230.56
\end{tabular}

${ }^{*}$ Results are expressed as mean $(\mathrm{n}=3) \pm$ standard deviation (SD). Results followed by the same lowercase letter in the row and the same uppercase letter in the column do not differ significantly (Tukey's test, $p<0.05$ ).

Jua pulp was found to be richer in soluble free ellagic acid (974 $\mu$ g ellagic acid/g DW). Although Kakadu plum exceeds this level, the concentration of ellagic acid in jua remains higher than other commercialized fruits, such as strawberry $(630 \mu \mathrm{g}$ ellagic acid/g DW), cranberry (120.0 $\mu$ g ellagic acid/g DW) and pomegranate [mesocarp, $234.2 \pm 13.0(\mathrm{dw})$ and peel $637.7 \pm 32.8(\mathrm{dw})]$. Walnuts (590 ellagic acid/g DW) are also popular sources of ellagic acid [16-18]. As a phenolic compound, ellagic acid can dampen oxidative stress, promoting numerous health benefits. For instance, this substance has been related to the prevention of cancer, diabetes, obesity, cardiovascular, gastrointestinal, and neurodegenerative diseases, among others. Therefore, plant material and agro-industrial by-products can serve as sources for the isolation of ellagic acid, which could be further purified and used in several areas, including cosmetics, feed formulation, nutraceuticals, and the food industry, acting as a natural antioxidant. The isolation and purification of this molecule can be performed by using conventional techniques, such as acid-solvent extraction with concentrated hydrochloric acid and methanol, or by more eco-friendly approaches. UAE, used in the present study, is an example of the latter, due to its low solvent usage, economical effectiveness, and reduced extraction time [19].

Since the extraction procedure does not render high selectivity, the recovery of a target compound (e.g., ellagic acid) needs to be followed by a purification step. Adsorption/desorption is widely used for purifying phenolic compounds. It involves the addition of the crude extract containing the target molecule through a column filled with the adsorbent material. Then, a desorption step is conducted with organic solvents (e.g., methanol, ethanol) to recover the phenolic of interest. Several adsorbents can be used, including activated carbon, resins, and polysaccharides, among others. Other techniques can be 
coupled with adsorption/desorption in order to further increase the compound's purity, such as ultrafiltration and nanofiltration, which work by size exclusion [20,21].

Therefore, the high concentration of ellagic acid in jua pulp extracts may render a significant contribution to its bioactive properties, classifying jua as an alternate source for the recovery of ellagic acid. Other sources of ellagic acid include pecans [22], Brazil nuts [23], fennel seed [24], mango seed, longan seed, pomegranate peel, walnuts' skin, and other underutilized fruits such as Canarium odontophyllum, Dacryodes rostrata, Mangifera pajang, and Parkia speciosa [25-28].

Gallic acid was the second most abundant compound, regardless of the solvent employed. The structural features of gallic acid, with three hydroxyl groups, also contribute to the strong antiradical activity of the molecule. Additionally, gallic acid has the ability to form inter- and intra-molecular hydrogen bonds, contributing to the stability of the compound. Similar to ellagic acid, the number of hydroxyl groups, free of steric hindrance, renders a high radical scavenging activity. The ability of gallic acid to minimize the excessive production of reactive oxygen species may result in a lower risk of developing neurodegenerative conditions, such as Parkinson's and Alzheimer's disease [29].

The HPLC-TPC (sum of all phenolics quantified in each extract obtained upon UAE) demonstrated that the aqueous and ethanolic extracts are richer in polyphenol content than the acetone extract. This result is in accordance with the trend previously observed for TPC values obtained by the spectrophotometric analysis (Table 1), lending support to the fact that water and ethanol are more efficient than acetone in extracting phenolic compounds from jua pulp under the experimental conditions employed. However, besides being an eco-friendly procedure, an aqueous medium is of great importance for food application.

\subsection{Antiradical Activity}

Table 3 shows the antiradical activity results of jua pulp extracts.

Table 3. Antiradical activity results for jua pulp extracts obtained by ultrasound-assisted extraction and continuous agitation, and oxygen radical absorbance capacity of selected fruits obtained from the literature.

\begin{tabular}{|c|c|c|c|c|c|c|c|c|c|c|c|c|}
\hline & \multicolumn{2}{|c|}{ Jua } & \multirow[t]{2}{*}{ Kiwi } & \multirow[t]{2}{*}{ Fig } & \multirow[t]{2}{*}{ Lucuma } & \multirow[t]{2}{*}{ Mango } & \multirow[t]{2}{*}{ Melon } & \multirow[t]{2}{*}{ Avocado } & \multirow[t]{2}{*}{ Pineapple } & \multirow[t]{2}{*}{ Banana } & \multirow[t]{2}{*}{ Watermelon } & \multirow[t]{2}{*}{ Grape } \\
\hline & $\begin{array}{l}\text { Ultrasound- } \\
\text { Assisted } \\
\text { Extraction * }\end{array}$ & $\begin{array}{l}\text { Continuous } \\
\text { Agitation * }\end{array}$ & & & & & & & & & & \\
\hline $\begin{array}{c}\text { Peroxyl radical } \\
\text { scavenging activity, } \\
\text { ORAC assay } \\
(\mu \mathrm{mol} \text { TE } / 100 \mathrm{~g})\end{array}$ & $\begin{array}{c}236 \pm 18.80 \\
\mathrm{a}_{\text {f.w. }}\end{array}$ & $\begin{array}{c}161.5 \pm 5.10 \\
b_{\text {f.w. }}\end{array}$ & - & - & - & - & - & - & - & - & - & - \\
\hline $\begin{array}{l}\text { Oxygen radical } \\
\text { absorbance } \\
\text { capacity }(\mu \mathrm{mol} \\
\mathrm{TE} / 100 \mathrm{~g})[30]\end{array}$ & $\begin{array}{l}10,926 \pm 870 \\
\text { d.w. }\end{array}$ & $\begin{array}{l}7475 \pm 236 \\
\text { d.w. }\end{array}$ & $\begin{array}{l}\text { 952-5860 } \\
\text { d.w. }\end{array}$ & $\begin{array}{l}\text { 953-6332 } \\
\text { d.w. }\end{array}$ & $\begin{array}{c}\text { 533-1152 } \\
\text { d.w. }\end{array}$ & $\begin{array}{c}\text { 322-1822 } \\
\text { d.w. }\end{array}$ & $\begin{array}{c}128-2299 \\
\text { d.w. }\end{array}$ & $\begin{array}{c}912-19,127 \\
\text { d.w. }\end{array}$ & $\begin{array}{l}968-7223 \\
\text { d.w. }\end{array}$ & $\begin{array}{c}1528-20,922 \\
\text { d.w. }\end{array}$ & $\begin{array}{l}\text { 193-1708 } \\
\text { d.w. }\end{array}$ & $\begin{array}{c}1085-19,819 \\
\text { d.w. }\end{array}$ \\
\hline
\end{tabular}

* Results are expressed as mean $(n=3) \pm$ standard deviation (SD). Results followed by the same lowercase letter in the row and the same uppercase letter in the column do not differ significantly (Tukey's test, $p<0.05$ ).

Similar to the trend observed for TPC, aqueous extracts obtained by UAE exhibited a higher scavenging activity towards peroxyl radicals $(236.0 \pm 10.80 \mu \mathrm{mol}$ TE/100 $\mathrm{g}$ fresh weight) than the extract obtained by CA $(161.5 \pm 5.10 \mu \mathrm{mol}$ TE/100 $\mathrm{g}$ fresh weight). The ORAC values of jua pulp obtained by UAE on a dry weight basis $(10,926 \mu \mathrm{mol}$ $\mathrm{TE} / 100 \mathrm{~g}$ ) were similar or higher than those of several fruits from the literature (e.g., fig, kiwi, lucuma, mango, melon, avocado, pineapple, banana, watermelon), including some types of grapes [30], which are references when it comes to the presence of phenolic antioxidants. Grapes, their products, and processing by-products have attracted much attention in the field. A recent study demonstrated that the ability of phenolic extracts in scavenging peroxyl radicals (ORAC method) led to being able to anticipate the biological properties of the test material in cell models [31]. Therefore, it is reasonable to suggest that, by showing higher ORAC values, jua pulp may provide greater health benefits than the mentioned fruits, although this assumption remains to be confirmed in animal models and/or human studies. Considering the importance of aqueous extraction in the context of 
green chemistry and food safety, the UAE was repeated using water, ethanol, and acetone and evaluated by a different method (ABTS radical cation) for confirmation. The results are shown in Table 4.

Table 4. Trolox equivalent antioxidant capacity (TEAC, $\mu \mathrm{mol} \mathrm{TE} / 100 \mathrm{~g} \mathrm{fw}$ ) of jua pulp extracts obtained by ultrasound-assisted extraction with water, ethanol, and acetone compared with results for methanol extracts from exotic fruits obtained from the literature.

\begin{tabular}{lllll}
\hline & Water & Ethanol & Acetone & Methanol [32] \\
\hline Jua & $1500 \pm 109$ & $840 \pm 59$ & $790 \pm 79$ & \\
Ciruela & - & - & - & $625 \pm 4$ \\
Jackfruit & - & - & - & $63 \pm 1$ \\
Mangaba & - & - & - & $1084 \pm 13$ \\
Murici & - & - & - & $1573 \pm 1$ \\
Papaya & - & - & - & $760 \pm 20$ \\
Pineapple & - & - & - & $378 \pm 3$ \\
Sapodilla & - & - & - & $69 \pm 11$ \\
Soursop & - & - & - & $621 \pm 62$ \\
Sweetsop & - & - & - & $832 \pm 11$ \\
Tamarind & - & - & - & $107 \pm 0$ \\
Umbu & - & & &
\end{tabular}

Results are expressed as mean $(n=3) \pm$ standard deviation (SD). Results followed by the same lowercase letter in the row and the same uppercase letter in the column do not differ significantly (Tukey's test, $p<0.05$ ).

Lending support to the finding obtained for TPC, UAE rendered the highest TEAC values (1500 $\pm 109 \mu \mathrm{mol} \mathrm{TE} / 100 \mathrm{~g}$ fresh weight), while no significant difference was found between ethanol $(840 \pm 59 \mu \mathrm{mol} \mathrm{TE} / 100 \mathrm{~g}$ fresh weight) and acetone $(790 \pm 79 \mu \mathrm{mol}$ $\mathrm{TE} / 100 \mathrm{~g}$ fresh weight). These results are in agreement with some of the TEAC results reported by Rufino [33] when studying several exotic fruits from Brazil. Açaí (1510 $\mu \mathrm{mol}$

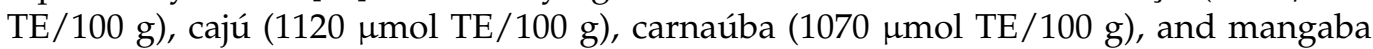
$(1460 \mu \mathrm{mol} \mathrm{TE} / 100 \mathrm{~g})$ showed similar findings to those reported in the present studies. Meanwhile, other fruits such as cajá $(780 \mu \mathrm{mol} \mathrm{TE} / 100 \mathrm{~g})$ and umbu $(630 \mu \mathrm{mol} \mathrm{TE} / 100 \mathrm{~g})$ were found to possess lower TEAC values than those of jua pulp extracts.

As mentioned earlier, ellagic acid was the main phenolic present in jua pulp (Table 2). The ability of different sources of ellagic acid to mitigate oxidative stress has also been reported owing to its scavenging activity towards hydroxyl radicals. This has also been related to their evidenced in vitro protection against DNA-damage and LDL-cholesterol oxidation, which are accepted as biomarkers for potential cancer development and risk of cardiovascular diseases, respectively [26,27]. Likewise, the anti-inflammatory effects of ellagic acid are supported by literature data. According to Chen et al. [34], ellagic acid effectively decreased IL-6 protein expression and cytokine release through inactivation of JNK and p65 pathways. Finally, the abilities of some sources of ellagic acid in inhibiting the activity related to the absorption of carbohydrates and lipids (e.g., alpha-glucosidase) and potential prevention of type 2 diabetes and obesity, as well as acetylcholinesterase, which has a key role in the development of Alzheimer's disease, have been reported [26,27,35].

\section{Materials and Methods}

\subsection{Samples and Chemicals}

Jua fruits (Ziziphus joazeiro M.) were collected from the city of Santa Rosa (Piaui, Brazil). The phenolic standards, namely phenolic acids (chlorogenic, caffeic, gallic, vanillic, trans-cinnamic, protocatechuic, hydroxybenzoic, ferulic, benzoic, salicylic, o-coumaric, p-coumaric, sinapic, gentisic, quinic, and ellagic acids), flavan-3-ols (catechin, epicatechin), flavonol (quercetin), and flavone (apigenin), were purchased from Sigma-Aldrich (São Paulo, Brazil). All other chemicals used in this study were obtained either from Sigma-Aldrich (São Paulo, Brazil), Carlo Erba (CER, São Paulo, Brazil), or Merck (Darmstad, Germany). 


\subsection{Determination of Vitamin C}

Ascorbic acid (vitamin C) was analyzed by the Tillmans method, based on the reduction of 2,6-dichlorophenol indophenol sodium salt (DISS) by ascorbic acid [36]. First, an ascorbic acid standard solution $(10 \mathrm{~mL})$ was mixed with an oxalic acid solution $(50 \mathrm{~mL})$. Then, the resulting mixture was titrated with the DISS solution. Subsequently, the same procedure was repeated by replacing the ascorbic acid solution with the samples. The amount of ascorbic acid was calculated according to the following equation:

$$
\text { Ascorbic acid }(\mathrm{mg} / 100 \mathrm{~mL})=\frac{V \times F \times 100}{A}
$$

where $V$ is the volume of Tillmans solution used in the titration, $F$ is the correction factor of the Tillmans solution, and $A$ is the sample volume $(\mathrm{mL})$.

In order to calculate the correction factor $(F)$, the amount of vitamin $C(\mathrm{mg})$ used in the titration was divided by the volume of Tillmans solution used $(\mathrm{mL})$.

\subsection{Phenolic Extraction}

Fresh fruit samples were used to obtain aqueous (distilled water), ethanolic (100\% ethanol), and acetone extracts (100\%) [37]. The samples (5 g) were mixed with $50 \mathrm{~mL}$ of solvent and homogenized with an Ultra-turrax dispenser for $1 \mathrm{~min}$. The mixtures were then submitted to either continuous agitation (CA) at $25^{\circ} \mathrm{C}$ for $1 \mathrm{~h}$ or ultrasound-assisted extraction (UAE-ELMA, Elmasonic P $60 \mathrm{H}$, Singen, Germany), at a frequency of $37 \mathrm{kHz}$, temperature of $25^{\circ} \mathrm{C}$, for $1 \mathrm{~h}$. Subsequently, the extracts were centrifuged at $3000 \times g$ rpm for $10 \mathrm{~min}$ at $20^{\circ} \mathrm{C}$. The supernatant was collected and stored in Ambar flasks under refrigeration $\left( \pm 4^{\circ} \mathrm{C}\right)$ until further analysis.

\subsection{Total Phenolic Content of Soluble Extracts}

This determination was performed according to Swain and Hillis [38]. Sample extracts $(0.5 \mathrm{~mL})$ were mixed with $8 \mathrm{~mL}$ of distilled water and $0.5 \mathrm{~mL}$ of Folin-Ciocalteu reagent. The content was homogenized, and after $3 \mathrm{~min}, 1 \mathrm{~mL}$ of a saturated sodium carbonate solution was added to the reaction tube. The mixture was allowed to react for $1 \mathrm{~h}$ in the dark, and the absorbance was read at $720 \mathrm{~nm}$. Total phenolic content was expressed as $\mathrm{mg}$ of gallic acid equivalents (GAE)/100 $\mathrm{g}$ of sample.

\subsection{Identification of Phenolic Compounds by High-Performance Liquid Chromatography (HPLC)}

The HPLC analysis of jua extracts was performed according to previous studies $[39,40]$. The HPLC apparatus (Shimadzu, LC20AT, Kyoto, Japan) consisted of an automated sample injector (SIL-20AC), controller (CBM-20), column oven (CTO-20), and diode array detector (SPD-M20A). A C18 stationary phase column (Shimadzu, Shim-Pack, VP-ODS-2, $25 \times 0.6 \mathrm{~cm}$, particle of $5 \mu \mathrm{m})$ was used. The mobile phase was composed of $0.1 \%(v / v)$ deionized water (A) and acetonitrile (B) in a proportion of 9.5 to 0.5 of $\mathrm{A}$ to $\mathrm{B}$. The gradient elution followed the order: $5 \%$ B (10 min), 5-100\% B (40 min), 100\% B (5 min). The oven temperature was kept at $35^{\circ} \mathrm{C}$, and the elution rate was set at $1 \mathrm{~mL} / \mathrm{min}$ during the analysis. The detection was performed between 190 and $400 \mathrm{~nm}$. The coefficients of determination (R2) ranged from 0.9925 to 0.9999 . The limits of detection (LOD) were in the range of 0.2 to $164.1 \mathrm{ng} \cdot \mathrm{mL}^{-1}$, while the limits of quantification (LOQ) ranged from 0.7 to $547.1 \mathrm{ng} \cdot \mathrm{mL}^{-1}$.

\subsection{Antiradical Activity towards Peroxyl Radicals}

For this determination, the protocol reported by Ou et al. [41], as adapted by Prior et al. [42], was followed. Prior to analysis, the fluorescein reagent was diluted with a phosphate buffer solution. An APPH [2,2'-azobis(2-methylpropionamidine) dihydrochloride] solution was also prepared with phosphate buffer. Subsequently, $50 \mu \mathrm{L}$ of sample was added to a microplate along with $150 \mu \mathrm{L}$ of fluorescein solution. The microplate was shaken and allowed to stand for $15 \mathrm{~min}$ at $37^{\circ} \mathrm{C}$, with a further addition of $50 \mu \mathrm{L}$ of AAPH solution. The microplate was once again shaken and allowed to react for $60 \mathrm{~min}$. The fluorescence 
detection (excitation: $485 \mathrm{~nm} / \mathrm{emission}: 535 \mathrm{~nm}$ ) was then read in a microplate reader (Molecular Devices, Sunnyvale, CA, USA). The results were expressed as $\mu \mathrm{mol}$ Trolox equivalents per $100 \mathrm{~g}$ of fruit ( $\mu \mathrm{mol} \mathrm{TE} / 100 \mathrm{~g}$ of fruit).

\subsection{Trolox Equivalent Antioxidant Capacity (TEAC)}

An ABTS ${ }^{\bullet+}$ solution was prepared by combining $7 \mathrm{mM}$ of ABTS with $2.45 \mathrm{mM}$ of potassium persulfate. The solution was allowed to react in the dark for $12 \mathrm{~h}$, being further diluted with ethanol until an absorbance value of $0.70 \pm 0.01$. The extract samples were also diluted with ethanol $(1: 5, v / v$ and $1: 10, v / v)$. Subsequently, $40 \mu \mathrm{L}$ of each diluted sample was mixed with $1960 \mu \mathrm{L}$ of a freshly prepared radical solution. The mixture reacted for $6 \mathrm{~min}$, and the absorbance was read at $734 \mathrm{~nm}$. Trolox solutions in ethanol were used as standards at concentrations of 20 and $50 \mu \mathrm{M}$. Ethanol alone was used as a control [43].

\subsection{Statistical Analysis}

The data $(\mathrm{n}=3)$ were analyzed by using the software ASSISTAT ( 7.6 beta). The analysis of variance (ANOVA) was calculated, and the means were compared using the Tukey test $(p<0.05)$.

\section{Conclusions}

Aqueous extracts obtained by ultrasound-assisted extraction showed the highest efficiency in the recovery of soluble phenolics, as supported by their total phenolic content, which may be attributed to the cavitation phenomenon promoted by the ultrasound. The HPLC analysis of jua pulp extracts showed that it was mainly composed of phenolic acids, ranging from $91 \%$ to $94 \%$, depending on the extraction solvent (water, ethanol, and acetone). Ellagic acid, which is known for its potent radical scavenging activity, was the most abundant phenolic ( $80 \%$ in the aqueous extract). The higher antiradical activity of the aqueous extracts obtained by UAE was confirmed by its ability to scavenge peroxyl radicals. This is the first report that demonstrates that jua can be a better source of ellagic acid than traditional sources such as strawberry, cranberry, and walnuts. Future studies should concentrate on the effects of food processing, digestibility, bioaccessibility, and bioavailability, and further biological activities of the fruit and its industrial products in animal models and/or clinical trials. For this, ellagic acid must be used as a target compound. Especially in the nutraceutical industry, which frequently deals with concentrated compounds and/or mixtures, toxicity testing must be contemplated.

Author Contributions: Conceptualization, T.S.d.R., A.d.L. and E.A.F.d.S.T.; methodology, T.S.d.R., A.d.L., E.A.F.d.S.T., J.d.N.S., G.R.S. and R.A.M.S.F; validation, G.R.S., R.A.M.S.F. and A.C.d.C.; formal analysis, T.S.d.R. and A.d.L.; investigation, T.S.d.R. and A.d.L.; resources, A.d.L. and E.A.F.d.S.T.; data curation, T.S.d.R. and A.d.L.; writing - original draft preparation, T.S.d.R. and A.d.L.; writingreview and editing, R.D., A.C.d.C., F.S. and E.A.F.d.S.T.; visualization, A.C.d.C. and R.D.; supervision, A.d.L. and E.A.F.d.S.T.; project administration, A.d.L. and E.A.F.d.S.T.; funding acquisition, A.d.L. and E.A.F.d.S.T. All authors have read and agreed to the published version of the manuscript.

Funding: This research was supported by CNPq (National Council for Scientific and Technological Development-Brazil)—Process 06/2011.

Institutional Review Board Statement: Not applicable.

Informed Consent Statement: Not applicable.

Data Availability Statement: The data presented in this study are available on request from the corresponding author.

Conflicts of Interest: The authors declare no conflict of interest.

Sample Availability: Samples of the compounds are not available from the authors. 


\section{References}

1. De Carvalho Romão, M.O. Avaliação da atividade protetora gástrica do extrato de raspa de juá. Rev. Soc. Bra. Clín. Med. 2010, 8, 222-227.

2. Silva, M.L.C.; Costa, R.S.; Santana, A.D.S.; Koblitz, M.G.B. Compostos fenólicos, carotenóides e atividade antioxidante em produtos vegetais. Semin. Ciênc. Agrárias 2010, 31, 669. [CrossRef]

3. Reiss, R.; Johnston, J.; Tucker, K.; Desesso, J.M.; Keen, C.L. Estimation of cancer risks and benefits associated with a potential increased consumption of fruits and vegetables. Food Chem. Toxicol. 2012, 50, 4421-4427. [CrossRef]

4. Shahidi, F.; Ambigaipalan, P. Phenolics and polyphenolics in foods, beverages and spices: Antioxidant activity and health effects-A review. J. Funct. Foods 2015, 18, 820-897. [CrossRef]

5. Liguori, I.; Russo, G.; Curcio, F.; Bulli, G.; Aran, L.; Della-Morte, D.; Gargiulo, G.; Testa, G.; Cacciatore, F.; Bonaduce, D.; et al Oxidative stress, aging, and diseases. Clin. Interv. Aging 2018, 13, 757-772. [CrossRef] [PubMed]

6. Grindel, A.; Müllner, E.; Brath, H.; Jäger, W.; Henriksen, T.; Poulsen, H.E.; Marko, D.; Wagner, K.-H. Influence of polyphenol-rich apple pomace extract on oxidative damage to DNA in type 2 diabetes mellitus individuals. Cancer Metab. 2014, 2, P25. [CrossRef]

7. Chemat, F.; Vian, M.; Cravotto, G. Green Extraction of Natural Products: Concept and Principles. Int. J. Mol. Sci. 2012, 13, 8615-8627. [CrossRef]

8. De Camargo, A.C.; Schwember, A.R.; Parada, R.; Garcia, S.; Maróstica, M.R.; Franchin, M.; Regitano-d'Arce, M.A.B.; Shahidi, F. Opinion on the Hurdles and Potential Health Benefits in Value-Added Use of Plant Food Processing By-Products as Sources of Phenolic Compounds. Int. J. Mol. Sci. 2018, 19, 3498. [CrossRef] [PubMed]

9. Chemat, F.; Rombaut, N.; Sicaire, A.-G.; Meullemiestre, A.; Fabiano-Tixier, A.-S.; Abert-Vian, M. Ultrasound assisted extraction of food and natural products. Mechanisms, techniques, combinations, protocols and applications. A review. Ultrason. Sonochem. 2017, 34, 540-560. [CrossRef]

10. Ma, Y.-Q.; Ye, X.-Q.; Fang, Z.-X.; Chen, J.-C.; Xu, G.-H.; Liu, D.-H. Phenolic compounds and antioxidant activity of extracts from ultrasonic treatment of Satsuma Mandarin (Citrus unshiu Marc.) peels. J. Agric. Food Chem. 2008, 56, 5682-5690. [CrossRef]

11. Sun, J.; Chu, Y.-F.; Wu, X.; Liu, R.H. Antioxidant and Antiproliferative Activities of Common Fruits. J. Agric. Food Chem. 2002, 50, 7449-7454. [CrossRef] [PubMed]

12. Iqbal, K.; Khan, A.; Khattak, M.M.A.K. Biological Significance of Ascorbic Acid (Vitamin C) in Human Health—A Review. Pak. J. Nutr. PJN 2004, 3, 5-13. [CrossRef]

13. Lima, R.D.S.; Ferreira, S.R.S.; Vitali, L.; Block, J.M. May the superfruit red guava and its processing waste be a potential ingredient in functional foods? Food Res. Int. 2019, 115, 451-459. [CrossRef]

14. Mazza, K.E.L.; Santiago, M.C.P.A.; do Nascimento, L.S.M.; Godoy, R.L.O.; Souza, E.F.; Brígida, A.I.S.; Borguini, R.G.; Tonon, R.V. Syrah grape skin valorisation using ultrasound-assisted extraction: Phenolic compounds recovery, antioxidant capacity and phenolic profile. Int. J. Food Sci. 2019, 54, 641-650. [CrossRef]

15. Muñiz-Márquez, D.B.; Wong-Paz, J.E.; Aguilar-Zárate, P.; Sepúlveda, L.; Buenrostro-Figueroa, J.; Ascacio-Valdés, J.A.; Aguilar, C.N. Effect of ultrasound on the extraction of ellagic acid and hydrolysis of ellagitannins from pomegranate husk. Environ. Technol. Innov. 2021, 24, 102063. [CrossRef]

16. Landete, J.M. Ellagitannins, ellagic acid and their derived metabolites: A review about source, metabolism, functions and health. Food Res. Int. 2011, 44, 1150-1160. [CrossRef]

17. Daniel, E.M.; Krupnick, A.S.; Heur, Y.H.; Blinzler, J.A.; Nims, R.W.; Stoner, G.D. Extraction, stability, and quantitation of ellagic acid in various fruits and nuts. J. Food Compost. Anal. 1989, 2, 338-349. [CrossRef]

18. Evtyugin, D.D.; Magina, S.; Evtuguin, D. Recent Advances in the Production and Applications of Ellagic Acid and Its Derivatives. A Review. Molecules 2020, 25, 2745. [CrossRef]

19. Muthukumaran, S.; Tranchant, C.; Shi, J.; Ye, X.; Xue, S.J. Ellagic acid in strawberry (Fragaria spp.): Biological, technological, stability, and human health aspects. Food Qual. Saf. 2017, 1, 227-252. [CrossRef]

20. Soto, M.L.; Moure, A.; Domínguez, H.; Parajó, J.C. Recovery, concentration and purification of phenolic compounds by adsorption: A review. J. Food Eng. 2011, 105, 1-27. [CrossRef]

21. Zagklis, D.P.; Paraskeva, C.A. Purification of grape marc phenolic compounds through solvent extraction, membrane filtration and resin adsorption/desorption. Sep. Purif. Technol. 2015, 156, 328-335. [CrossRef]

22. Alvarez-Parrilla, E.; Urrea-López, R.; de la Rosa, L.A. Bioactive components and health effects of pecan nuts and their byproducts: A review. J. Food Bioact. 2018, 1, 56-92. [CrossRef]

23. Sartori, A.G.O.; Regitano-d'Arce, M.A.B.; Skibsted, L.H. Brazil nut: Nutritional benefits from a unique combination of antioxidants. J. Food Bioact. 2019, 9, 36-39. [CrossRef]

24. Shahidi, F.; Hossain, A. Bioactives in spices, and spice oleoresins: Phytochemicals and their beneficial effects in food preservation and health promotion. J. Food Bioact. 2018, 3, 8-75. [CrossRef]

25. Mirfat, A.H.S.; Amin, I.; Kartinee, K.N.; Muhajir, H.; Shukri, M.A.M. Underutilised fruits: A review of phytochemistry and biological properties. J. Food Bioact. 2018, 1, 2-30. [CrossRef]

26. Ambigaipalan, P.; de Camargo, A.C.; Shahidi, F. Phenolic compounds of pomegranate byproducts (outer skin, mesocarp, divider membrane) and their antioxidant activities. J. Agric. Food Chem. 2016, 64, 6584-6604. [CrossRef]

27. Ambigaipalan, P.; Camargo, A.C.d.; Shahidi, F. Identification of phenolic antioxidants and bioactives of pomegranate seeds following juice extraction using HPLC-DAD-ESI-MSn. Food Chem. 2017, 221, 1883-1894. [CrossRef] [PubMed] 
28. De Oliveira, F.L.; Arruda, T.Y.P.; Lima, R.d.S.; Casarotti, S.N.; Morzelle, M.C. Pomegranate as a natural source of phenolic antioxidants: A review. J. Food Bioact. 2020, 9, 10-22. [CrossRef]

29. Badhani, B.; Sharma, N.; Kakkar, R. Gallic acid: A versatile antioxidant with promising therapeutic and industrial applications. RSC Adv. 2015, 5, 27540-27557. [CrossRef]

30. Portal Antioxidantes. Available online: http://portalantioxidantes.com/ (accessed on 10 December 2020).

31. De Camargo, A.C.; Biasoto, A.C.T.; Schwember, A.R.; Granato, D.; Rasera, G.B.; Franchin, M.; Rosalen, P.L.; Alencar, S.M.; Shahidi, F. Should we ban total phenolics and antioxidant screening methods? The link between antioxidant potential and activation of NF- $\mathrm{BB}$ using phenolic compounds from grape by-products. Food Chem. 2019, 290, 229-238. [CrossRef]

32. Almeida, M.M.B.; de Sousa, P.H.M.; Arriaga, Â.M.C.; do Prado, G.M.; Magalhães, C.E.d.C.; Maia, G.A.; de Lemos, T.L.G. Bioactive compounds and antioxidant activity of fresh exotic fruits from northeastern Brazil. Food Res. Int. 2011, 44, 2155-2159. [CrossRef]

33. Rufino, M.d.S.M.; Alves, R.E.; de Brito, E.S.; Pérez-Jiménez, J.; Saura-Calixto, F.; Mancini-Filho, J. Bioactive compounds and antioxidant capacities of 18 non-traditional tropical fruits from Brazil. Food Chem. 2010, 121, 996-1002. [CrossRef]

34. Hui-Chi, C.; Yu-Tang, T.; Sheng-Yi, C.; Jer-An, L.; Gow-Chin, Y. Effect of Phyllanthus emblica L. fruit on improving regulation of methylglyoxal-induced insulin resistance in 3T3-L1 cells. J. Food Bioact. 2018, 4, 139-149.

35. Morzelle, M.C.; Salgado, J.M.; Massarioli, A.P.; Bachiega, P.; Rios, A.O.; Alencar, S.M.; Schwember, A.R.; de Camargo, A.C. Potential benefits of phenolics from pomegranate pulp and peel in Alzheimer's disease: Antioxidant activity and inhibition of acetylcholinesterase. J. Food Bioact. 2019, 5, 136-141. [CrossRef]

36. Instituto Adolfo Lutz. Métodos Físico-Químicos Para Análise de Alimentos; Instituto Adolfo Lutz: São Paulo, Brazil, 2008.

37. Larrauri, J.A.; Ruperez, P.; Saura-Calixto, F. Effect of drying temperature on the stability of polyphenols and antioxidant activity of red grape pomace peels. J. Agric. Food Chem. 1997, 45, 1390-1393. [CrossRef]

38. Swain, T.; Hillis, W.E. The phenolic constituents of Prunus domestica. I.-The quantitative analysis of phenolic constituents. J. Sci. Food Agric. 1959, 10, 63-68. [CrossRef]

39. Pereira, C.A.M.; Yariwake, J.H.; Lanças, F.M.; Wauters, J.N.; Tits, M.; Angenot, L. A HPTLC densitometric determination of flavonoids from Passiflora alata, P. edulis, P. incarnata and P. caerulea and comparison with HPLC method. Phytochem. Anal. 2004, 15, 241-248. [CrossRef]

40. Tiberti, L.A.; Yariwake, J.H.; Ndjoko, K.; Hostettmann, K. Identification of flavonols in leaves of Maytenus ilicifolia and M. aquifolium (Celastraceae) by LC/UV/MS analysis. J. Chromatogr. B 2007, 846, 378-384. [CrossRef]

41. Ou, B.; Hampsch-Woodill, M.; Prior, R.L. Development and validation of an improved oxygen radical absorbance capacity assay using fluorescein as the fluorescent probe. J. Agric. Food Chem. 2001, 49, 4619-4626. [CrossRef]

42. Prior, R.L.; Hoang, H.; Gu, L.; Wu, X.; Bacchiocca, M.; Howard, L.; Hampsch-Woodill, M.; Huang, D.; Ou, B.; Jacob, R. Assays for hydrophilic and lipophilic antioxidant capacity (oxygen radical absorbance capacity (ORAC(FL))) of plasma and other biological and food samples. J. Agric. Food Chem. 2003, 51, 3273-3279. [CrossRef]

43. Re, R.; Pellegrini, N.; Proteggente, A.; Pannala, A.; Yang, M.; Rice-Evans, C. Antioxidant activity applying an improved ABTS radical cation decolorization assay. Free Radic. Biol. Med. 1999, 26, 1231-1237. [CrossRef] 